\title{
A Educação do Campo na Perspectiva da Educação Popular
}

\author{
Márcia Eliana Ziech ${ }^{1}$
}

\begin{abstract}
Resumo:
0 texto trata da educação do campo na perspectiva da educação popular, contemplando a educação realizada na escola do campo da rede estadual no município de Giruá/RS, que com o transcorrer do tempo vem passando por significativas modificações. Estas mudanças começaram a aparecer nos anseios pedagógicos a partir do momento em que a educação entrou em pauta nas lutas sociais, e receberam maior relevância e importância com a regulamentação de legislações que dão respaldo para a estruturação e ressignificação do processo de ensino-aprendizagem das escolas do campo. Com base em Arroyo (2004), a educação das escolas do campo é ressignificada a partir dos saberes populares do grupo no qual a escola está inserida. Assim, compreende-se que a escola do campo tem a família e os órgãos públicos, como Emater, Secretarias Municipal de Agricultura e Meio Ambientee Sindicato dos Trabalhadores Rurais, como parceiros no processo ensino-aprendizagem. Este processo não está mais restrito às paredes da escola e nem a sua vizinhança, mas vai do local para o global, usando-se de espaços externos, inclusive nas propriedades dos alunos como extensão do espaço de aprendizagem escolar, sendo possível identificar no currículo e no trabalho pedagógico realizado na escola a relação que se estabelece com os saberes populares da comunidade onde está inserida. A pesquisa é de cunho qualitativo e está fundamentada bibliograficamente em Arroyo, Caldart, Molina, Lopes e Macedo, Silva e Streck. Realizada a partir do método dialético, de forma documental, e faz o levantamento e produção de dados a partir da observação do trabalho pedagógico da única escola do campo da rede estadual no município de Giruá/RS. Após a realização da pesquisa, foi identificado que a relação com os saberes populares se dá de forma mais efetiva na condução e ênfase do trabalho pedagógico, voltando os conhecimentos científicos e os conteúdos escolares para a realidade do campo, e usando situações do cotidiano das propriedades rurais como desencadeador de situações de aprendizagens.
\end{abstract}

Palavras-chave: Currículo. Educação. Escola do Campo. Educação Popular.

\footnotetext{
${ }^{1}$ Mestranda no Mestrado em Educação nas Ciências da Unijuí. Bolsista institucional, especialista em Supervisão Escolar e em Psicopedagogia. Pedagoga, professora do Ensino Fundamental da rede estadual de ensino.marciaziech@bol.com.br
} 
THE EDUCATION OF THE FIELD IN THE PERSPECTIVE OF POPULAR EDUCATION

\begin{abstract}
The text deals with rural education perspective of popular education, contemplating education held at the country school of the field of the state network in the municipality of Giruá/ RS, that with the passage of time has been undergoing significant modifications. These changes began to appear in pedagogical yearnings from the moment in which education entered into the agenda of social struggles,and received greater relevanceand importance with the regulation of legislation that support the for structuringand re-signification of the process of teaching-learning of rural schools. Based on Arroyo (2004), the education of the rural schools are redefined from the popular knowledge of the group where the school is inserted. Like this, it is understood that the rural school has family and public bodies, as Emater, Municipal Secretarias of Agriculture and Environment, and Union of Rural Workers as partners in the teaching-learning process. This process is no longer restricted on school walls and neither is its neighborhood, but goes from the local to the global, using external spaces, including the properties of students as an extension of the school learning space. It is possible to identify in curriculum and pedagogical work held at school the relationship that is established with the popular knowledge of the community where it is inserted. The research is qualitative and is based bibliographically in Arroyo, Caldart, Molina, in Lopes and Macedo, in Silva and in Streck. Made from the dialectical method, in documentary form and does the survey and data production from the observation of the pedagogical work of the country's only school of the state network in the city of Giruá/RS. After conducting the research, was identified that the relationship with popular knowledge is more effective in driving and emphasis of pedagogical work,returning scientific knowledge and the school contents for the reality of the field, and using everyday situations of rural properties as a trigger for learning situations.
\end{abstract}

Keywords: Curriculum. Education. Schoolfield. Popular Education. 
A Educação do Campo vem nos últimos anos passando por uma reflexão pedagógica quanto a sua função social e de formação dos sujeitos do campo. Esta mudança de pensamento e de relação com os saberes populares vem inquietando os professores e a escola do campo da rede estadual do município de Giruá/RS. A concepção educação do campo surge com uma nova práxis, na qual os sujeitos do campo não são apenas receptores de uma educação urbana, mas sujeitos que se constituem a partir do seu contexto rural/local ao global. Assim, a educação do campo percebe os sujeitos em suas raízes, sua história, sua cultura, sua relação com o meio e com o coletivo, como aquele sujeito que busca a compreensão de si para, então, compreender o mundo, de forma a compreender as suas raízes, a sua história, sua relação com o meio e com o coletivo, sua cultura, assim compreendendo a si para então compreender o mundo. Neste contexto, Arroyo, Caldart e Molina (2004, p. 12) afirmam que:

Aqui se entende por Educação do Campo. Um movimento de ação, intervenção, reflexão, qualificação que tenta dar organicidade e captar, registrar, explicitar e teorizar sobre múltiplos significados históricos, políticos e culturais consequentemente formadores, educativos.

A Educação do Campo, então, é uma ação, que vai intervir de forma reflexiva para organizar, buscar, experimentar e teorizar qualitativamente os diversos significados e conhecimentos históricos, políticos e culturais do povo do campo, para ir em busca de novas possibilidades. Essa definição de Educação do Campo vem ao encontro do que propõe a Educação Popular, que, como concepção e/ou metodologia, defende a ideia de partir dos saberes populares do grupo de indivíduos a quem se destina, e ir além, propiciando novos conhecimentos e novas aprendizagens e compreensões, ampliando os conhecimentos previamente já vivenciados.

A Educação Popular é aqui referida na dinâmica da Educação do Campo, pois se refere a grupos distintos de moradores e trabalhadores do campo. É a partir disso que refletir sobre Educação do Campo nos remete a compreender que este tipo de educação é construída, definida, pensada e tem sua ação vinda dos saberes populares e, com base neles, viabiliza o contato com os conhecimentos planetários, ou seja, fazer a dialógica entre o local e o global. 
A Educação do Campo surge na dinâmica dos grupos que vivem no campo, por intermédio das suas organizações e de seus movimentos em prol dos direitos do povo do campo. Compreende-se aqui, como povo do campo, todos aqueles que possuem relação direta com a vida no campo: agricultores familiares, pequenos agricultores, camponeses, trabalhadores rurais, sem-terra, enfim, todos que vivem ou sobrevivem do trabalho no campo. Esses grupos, por meio das suas lutas sociais, incorporaram junto as lutas por uma educação de qualidade para seus filhos, não aceitando mais a escola rural como uma "escolinha" sem condições, sem material, sem intenção pedagógica, uma escola de poucas letras.

A escola do campo é uma escola que se diferencia das demais escolas pelas características que assume, diante do contexto e das necessidades de educação que possui, pois tem especificidade própria que a identifica, com intencionalidade específica e voltada ao espaço cultural e social onde está inserida. Ela compreende várias questões sociais, econômicas, de meio ambiente e de formação do ser humano se relacionando entre si e com o espaço físico e social. Arroyo, Caldart e Molina (2004, p. 100-101), assim apresentam o trabalho na terra como aprendizagem importante:

O trabalho na terra, que acompanha o dia-a-dia do processo que faz de uma semente uma planta e da planta um alimento, ensina de um jeito muito próprio que as coisas não nascem prontas, mas, sim, que precisam ser cultivadas: são as mãos do camponês, da camponesa, as que podem lavrar a terra para que chegue a produzir o pão. Este também é um jeito de compreender que o mundo está para ser feito e que a realidade pode ser transformada, desde que esteja aberto para que ela mesma diga a seus sujeitos como fazer isto, assim como a terra vai mostrando ao lavrador como precisa ser trabalhada para ser produtiva.

Devemos compreender que o mundo não está pronto, mas em constante mudança e que estamos integrados a esta transformação, de forma que, ao mesmo tempo, nos transformamos e interferimos na modificação do mundo. Aprender a cultivar, cuidar, fazer produzir são fundamentos importantes que as famílias do campo têm para contribuir com a escola, para esta transformar esses ensinamentos relativos a sementes e a terra evoltá-los ao cultivo e ao cuidado 
com os seres humanos. Com esse entendimento, percebemos que a educação do campo leva as peculiaridades e os ensinamentos populares que as famílias e a comunidade trazem consigo, e que vão passando de geração em geração, mas muito disso na forma oral deixando muito pouco como registro, e são conhecimentos importantes, base para conduzir o aprendizado.

Partindo da ideia de evolução e de transformação, torna-se importante uma pequena retomada das mudanças históricas que marcaram as modificações que vêm ocorrendo nas escolas do campo, principalmente nos últimos anos. A escola do campo que temos hoje não é mais a escola de décadas atrás. A escola mudou e com ela a importância que assume, a intencionalidade que tem e a forma de trabalhar em prol da formação das novas gerações do campo.

\section{Voltando um Pouco no Tempo}

Até a década de 60 as escolas localizadas no meio rural eram nomeadas de Escolas Rurais Isoladas. Elas contavam, geralmente, com apenas uma ou duas professoras que lecionavam a muitos alunos em uma sala bem grande, onde todas as idades cronológicas e de aprendizagem estavam juntas lado a lado. Neste período da história da Educação do Campo, muitos professores atendiam os alunos sem a preocupação real com a aprendizagem; aprendia quem queria ou conseguia. Os saberes eram concentrados em ler, escrever e fazer cálculos, e aqui era a intencionalidade maior, porque a aprendizagem era feita de tal forma que os alunos desenvolviam com mais destreza a capacidade do cálculo mental, ressaltando que aprendia quem tinha aptidão.

A Escola Rural Isolada não era nem pensada nem considerada pela mantenedora. A infraestrutura era muito precária; não possuíam espaço e mobiliário adequados nem material escolar. A prática pedagógica contava com a criatividade do professor que, em sua maioria, eram leigos;tinham apenas a sua disposição em ensinar, quadro e giz. O professor contava também com o apoio das famílias que eram bem-presentes, principalmente quando se tratava de limites, valores e educação. 
A situação de falta de recursos deixava o fazer pedagógico voltado ao que o professor poderia executar. O professor não tinha um assessoramento pedagógico nem orientações pedagógicas no trabalho e atendimento dos alunos. Isso fazia com que o fracasso escolar fosse crescente e deixava as famílias não acreditando na educação da época, mas era o que tinham no momento. Poucos alunos conseguiam cursar todas as séries disponíveis na escola, pois levavam muito tempo para cursá-las; logo cresciam e tinham de ajudar no trabalho de casa, e assim evadiam.

Depois de muitas lutas e de movimentos sociais, a educação do campo passa a ser pensada com mais ênfase. Com a Constituição de 1988, amplia-se e consolida-se o compromisso do Estado e da sociedade com a educação para todos. Isso fez com que vários segmentos da sociedade começassem a se preocupar com o acesso à educação das diferentes classes sociais e dos diferentes lugares. Com isso, a educação escolar é ampliada tornando-se obrigatório o Ensino Fundamental até os 17 anos. Com a interferência do Poder Judiciário, em defesa dos Direitos da Criança e do Adolescente, muitas crianças e adolescentes foram obrigados a retornar aos estudos, obrigando os governos a ampliar o atendimento educacional nas zonas rurais dos municípios, mas isso não aconteceu em todos os lugares. Na escola do campo pesquisada o Ensino Fundamental foi ampliado para séries finais, feita de forma gradativa a partir de $1990 .^{2}$

O fazer pedagógico não foi organizado e nem estruturado nas/pelas escolas que passaram por esse processo. Inicialmente, ampliar o acesso se deu apenas para cumprir uma determinação legal, sem pensar na qualidade e na intencionalidade deste processo para as populações do campo. Muitas vezes a educação realizada nas escolas foi apenas uma cópia da educação urbana, que era ministrada nas escolas das cidades. Isso em muito, dificultou a aprendizagem dos alunos, pois os interesses eram diferentes. Enquanto eles queriam saber e conhecer sobre formas de produção, de cultivar a terra e de cuidados com o meio ambiente dentro do processo de produção da agricultura, a escola vinha com conteúdos urbanos e fora do contexto de vida dos alunos. Isso fez com que a

\footnotetext{
2 Dados produzidos a partir do histórico da escola do campo da rede estadual do município de Giruá/RS, contido nos documentos e transcrito para o Projeto Político Pedagógico.
} 
exclusão e até a repetência em grande escala, viessem acompanhando o aumento deste nível de ensino. Justificando o fracasso escolar na falta de competência para a aprendizagem das crianças e adolescente do meio rural, tendo e reafirmando o preconceito de que para este tipo de clientela educativa não é necessário muito empenho nem muito desenvolvimento, ou seja, de qualquer forma está bom. Miguel Arroyo (2004, p. 72 apud ARROYO, CALDART, MOLINA, 2004) escreveu sobre sua experiência enquanto aluno de uma escola do campo:

Eu estudei numa escola rural. Sou filho de uma família rural, minha mãe continua lá, na cidadezinha onde nasci, cuidando de galinha, de coelhos, plantando a vinha, colhendo uva, fazendo um vinho maravilhoso. Meu pai viveu sua vida inteira muito apaixonado pela plantação de vinho, morreu colhendo a uva. Estudei numa escola rural. Lembro da minha escola, não como uma escolinha pobre do "cai não cai", apenas das primeiras letras. Tenho uma lembrança muito boa da minha experiência na escola rural e é por isso que falo apaixonado que é possível uma nova escola. É possível recuperar a educação básica, recuperar o saber, a cultura, a ética, recuperar os valores próprios de uma educação básica no campo.

Este depoimento de Arroyo (2004) mostra um sentimento importante e que é comum para muitos alunos de escolas do campo. As lembranças que ficaram das vivências numa escola do campo são permeadas por sentimentos de carinho com o espaço e com as pessoas que conviveram neste lugar tão especial. Em relação, todavia ao conhecimento, aos saberes e aos materiais didáticos e pedagógicos que as escolas tinham à disposição, este sentimento não é o mesmo.

A educação, ministrada sem um planejamento pedagógico específico, não contemplou os interesses da população do campo, apenas executou uma determinação. Com o passar dos anos, e percebendo as falhas político-pedagógicas deste ensino, começou-se a refletir sobre o que levava os alunos a terem insucesso na escola do campo. Os movimentos sociais do campo tinham um discurso de valorização do espaço rural, enquanto na escola do campo isso ainda não tinha chegado. A Lei de Diretrizes e Bases da Educação Nacional 9394/96, já introduziu algumas mudanças referentes à educação do campo, mas,somente a partir de 2004, as coisas começaram a mudar, principalmente a partir da realização de 
Conferências Nacionais por uma Educação Básica do Campo. ${ }^{3}$ A partir daí, o estudo e o compromisso com a Educação do Campo passaram a ter outro grau de relevância nos poderes públicos, na sociedade e na própria escola do campo, que,em muitos casos, deixou de ser apenas uma cópia da escola urbana, para começar a assumir o seu protagonismo social.

A criação, em 2004, no âmbito do Ministério da Educação, da Secretaria de Educação Continuada, Alfabetização e Diversidade, à qual está vinculada a Coordenação Geral de Educação do Campo, significa a inclusão na estrutura estatal federal de uma instância responsável, especificamente, pelo atendimento dessa demanda a partir do reconhecimento de suas necessidades e singularidades (BRASIL, 2007, p. 12).

A criação de órgãos dentro das esferas governamentais federais, estaduais e municipais, mostra que a população do campo começa a receber uma atenção um pouco melhor. As escolas passam a ser mais estruturadas com infraestrutura melhorada, mais materiais e equipamentos, facilitando o trabalho pedagógico, no sentido, de diversificar as formas de conduzir as aulas. Em âmbito federal temos, por meio do Fundo Nacional de Desenvolvimento da Educação (FNDE) no programa Dinheiro Direto na Escola, o recebimento de verbas específicas destinadas para Escolas do Campo para investimentos e melhorias na educação e na infraestrutura.

Os investimentos financeiros e de legislação que regulamentam a Educação do Campo, vêm sendo ampliados e recebendo uma atenção especial, pois atendem muitos alunos e alcançam dentro das realidades rurais as crianças em seus contextos específicos. De acordo com a Resolução $\mathrm{N}^{\circ}$ 4, de 13 de julho

\footnotetext{
3 A Conferencia Nacional por Uma Educação Básica no Campo aconteceu em Luiziânia-GO, de 21 a 23 de julho de 1998. Entre os compromissos e desafios contidos no documento final está que somente é possível trabalhar por uma educação básica no campo vinculada ao processo de construção de um Projeto Popular para o Brasil, que inclui, necessariamente, um novo projeto de desenvolvimento para o campo e a garantia de que todo o povo tenha acesso à educação (ARROYO; CALDART; MOLINA, 2004).
} 
de 2010, que define Diretrizes Curriculares Nacionais Gerais para a Educação Básica, dentro das modalidades da Educação Básica, na Seção IV - Educação do Campo, apresenta-se:

Art. 35. Na modalidade de Educação Básica do Campo, a educação para a população rural está prevista com adequações necessárias às peculiaridades da vida do campo e de cada região, definindo-se orientações para três aspectos essenciais à organização da ação pedagógica.

I - conteúdos curriculares e metodologias apropriadas às reais necessidades e interesses dos estudantes da zona rural;

II - organização escolar própria, incluindo adequação do calendário escolar às fases do ciclo agrícola e às condições climáticas;

III - adequação à natureza do trabalho na zona rural (BRASIL, 2013, p. 73).

Assim, cada vez mais a educação do campo recebe um olhar mais especial, pois é garantido com base na resolução, possibilidades de adequações importantes quanto ao cumprimento do tempo e diferentes formas de gerir este tempo, considerando características específicas de cada lugar, de produção, de ciclo agrícola e de clima. Isso possibilita às escolas criarem o calendário escolar coerente com as possibilidades que os alunos têm de frequentarem as aulas, tendo dias letivos e carga horária respeitados e primando pela qualidade deste tempo. Ainda, o artigo 36 da Resolução trata da identidade da escola do campo.

A identidade da escola do campo é definida pela vinculação com as questões inerentes à sua realidade, com propostas pedagógicas que contemplem sua diversidade em todos os aspectos, tais como sociais, culturais, políticos, econômicos, de gênero, geração e etnia.

Parágrafo único. Formas de organização e metodologias pertinentes à realidade do trabalho devem ter acolhidas, como a pedagogia da terra, pela qual busca um trabalho pedagógico fundamentado no princípio da sustentabilidade, para assegurar a preservação da vida das futuras gerações, e a pedagogia da alternância, na qual o estudante participa, concomitantemente e alternadamente, de dois ambientes/situações de aprendizagem: o escolar e o laboral, supondo parceria educativa, em que ambas as partes são corresponsáveis pelo aprendizado e pela formação do estudante (BRASIL, 2013, p. 73). 
Isso remete a pensar a escola do campo a partir do contexto onde está inserida, pois a realidade social, cultural, política, econômica, inclusive questões de gênero, de gerações e questões étnicas, são fundamentais para a construção da identidade da escola, das formas de trabalho pedagógico, das intencionalidades e, principalmente, nas relações que a escola estabelece com as famílias e com a comunidade escolar. Os vínculos e a participação efetiva que se firmam definem e dão sustentabilidade para a proposta pedagógica que a escola cria com a sua comunidade.

\section{Um Novo Olhar para a Educação da Escola do Campo}

A partir dos movimentos em prol da Educação do Campo, houve novos ânimos. O pedagógico das escolas do campo passou a receber um olhar mais crítico percebendo que a ação educativa precisa ser pensada a partir da realidade social-político-cultural do grupo a que se destina, tendo uma intencionalidade, uma formação voltada ao campo, não restrito ao campo, mas partindo dele.

Quando a educação do Campo passou a ser contemplada especificamente na legislação brasileira, efetivamente se passou a olhá-la com olhos mais críticos, cobrando das diferentes esferas governamentais a melhora no atendimento das crianças e adolescentes do campo.

A LDB de 1996 reconhece, em seus arts. $3^{\circ}, 23,27$ e 61, a diversidade sociocultural e o direito à igualdade e à diferença, possibilitando a definição de diretrizesoperacionais para a educação rural sem, no entanto, romper com um projeto global de educação para o país (BRASIL, 2007, p. 16).

Isso possibilitou que cada realidade do campo pudesse adequar-se conforme suas possibilidades e especificidades, pois o espaço territorial do país é muito grande, com diferentes climas e situações, com épocas de trabalho no campo, dando liberdade para que cada escola e região definam como vão desenvolver as atividades pedagógicas e atender às questões legais que regem a Educação Básica de todo o país. 
Com isso, teve-se oportunidade de criar diferentes calendários escolares que respeitam clima e épocas de trabalho no campo, pois, em muitos casos, os jovens ajudam seus pais na rotina da propriedade. Isso possibilita a cada contexto diferenciado a adequação do fazer pedagógico, pensado de forma crítica a partir dos saberes, da cultura, das tradições, do meio em que este grupo se insere, refletindo sobre formas de produção, compreensão e preservação do meio ambiente aliado à produção agrícola e de pecuária, mas isso compreende tomar como referência a formação de sujeitos crítico, que compreendem sua realidade e possam ver, a partir daí, possibilidades para produzir e viver no campo. Segundo Arroyo (2004, p. 13 apud ARROYO; CALDART; MOLINA, 2004).

É preciso educar um modelo de agricultura que inclui os excluídos, que amplia os postos de trabalho, que aumenta as oportunidades do desenvolvimento das pessoas e das comunidades e que avança na produção e na produtividade centradas em uma vida mais digna para todos e respeitadora de limites da natureza.

É desse pensamento inclusivo que a escola precisa, porque é nela que acontece o desenvolvimento das novas gerações que irão viver no campo. Ter amor, respeito pelo ambiente é a premissa fundamental para aquele que quer viver do/no campo, e essa é uma tarefa da escola. Educar as novas gerações requer um comprometimento com o futuro, que perpassa por todas as áreas do conhecimento, compreendidas como integrantes de um todo e pensadas coletivamente, de forma a complementar a ação de uma com a ação da outra. $O$ fazer pedagógico é um fazer coletivo, de todo o grupo, e também da sociedade onde a escola está inserida, pois o pensamento coletivo e as intencionalidades deste fazer precisam ser uma definição deste coletivo. Assim, questões importantes como os valores, a história e as raízes culturais do campo precisam ser consideradas na educação do campo. Miguel Arroyo (2004, p. 80 apud ARROYO; CALDART; MOLINA, 2004) coloca que:

Quando situamos a educação como um processo de transformação humana, de emancipação humana, percebemos quanto os valores do campo fazem parte da história da emancipação humana. Então, como a escola vai trabalhá-los? 
Será que a escola vai ignorá-los? A questão é mais fundamental, é ir às raízes culturais do campo e trabalhá-las, incorporá-las como uma herança coletiva que mobiliza e inspira lutas.

Nesse sentido, a escola precisa considerar os ensinamentos do campo e principalmente, os valores do campo, que perpassam as gerações e fazem parte da construção do humano como humano. As culturas e as tradições dos grupos do campo são fundamentais na construção e desenvolvimento do conhecimento na escola.

É a partir desse olhar que a pesquisa realizada ganha importância, pois tem como objetivo identificar no currículo e no trabalho pedagógico realizado na escola do campo a relação que se estabelece com os saberes populares da comunidade onde está inserida, percebendo na documentação da escola, principalmente no Projeto Político Pedagógico como esta questão está sendo abordada. Assim, observa-se no trabalho pedagógico a efetivação desta ideia; se há ou não conexões com os saberes populares e as relações que se estabelecem a partir deles.

Antes da realização da parte empírica foi realizado um levantamento para verificar o que já se tem produzido sobre o tema Educação do Campo na perspectiva da Educação Popular. O levantamento foi realizado no Portal de Periódicos da Capes, usando os descritores educação do campo e saberes populares; foram encontradas 4 produções. Destas, um trabalho tinha relação com o tema pesquisado. Uma nova busca foi feita com os descritores educação do campo e educação popular, e foram identificadas 113 produções, e destas 13 tinham relação com o tema pesquisado. $\mathrm{O}$ estado da arte da pesquisa vem reforçar a necessidade de realização de novas pesquisas e trabalhos voltados à educação do campo.

A pesquisa de cunho qualitativo foi baseada no método dialético, que, ao coletar e analisar os dados, considera o contexto social e cultural das situações analisadas. A pesquisa documental teve como base os documentos da escola, principalmente o Projeto Político Pedagógico e os Planos de Estudos, além do levantamento e produção de dados a partir da observação do trabalho pedagógico. 
A partir dos dados produzidos com os documentos e observação do trabalho pedagógico, foram cruzadas as informações para analisar o currículo realizado na escola do campo, para apontar as relações que têm com a cultura e os saberes locais, e ver como se estabelecem esses conhecimentos com os conhecimentos e conteúdos científicos produzidos pela humanidade.

Pensar na educação das novas gerações requer ir além do próprio espaço da sociedade onde a escola está inserida. Ir do local ao global é uma necessidade. Com as tecnologias disponíveis e a globalização regendo o mundo, temos de nos adequar e propiciar aos alunos idas e vindas do contexto local ao contexto global. Milton Santos (2012, p. 339) afirma que "Cada lugar é, ao mesmo tempo, objeto de uma razão global e de uma razão local, convivendo dialeticamente.'Propiciar a compreensão do todo com base na parte vivida, criar condições de escolhas e entendimento mais reais, principalmente quando se fala em crianças e adolescentes, é fundamental. A questão do real e da abstração precisa ser pensada conforme a capacidade de desenvolvimento em que o aluno está. Assim, cabe ao professor ter conhecimento sobre o desenvolvimento humano para saber das formas e condições para abordar os diferentes assuntos em sala de aula, mas tendo em mente, que o local é a base, e que a partir dele vai ao global.

A Educação do Campo, a partir daí, ganha o cunho da Educação Popular, pois parte dos conhecimentos já desenvolvidos e adquiridos pelos integrantes deste grupo. Os conhecimentos populares são o fundamento para a relação com os conhecimentos científicos, possibilitando conhecer o seu local para interpretar o global. As formas de relação, o meio ambiente, o tempo, o espaço, o clima, o relevo, as histórias, as tradições, a cultura, a religiosidade dos grupos, mostram o conhecimento prévio que possuem, e a partir deles podem estabelecer relações com outros espaços-lugares-tempos, fazendo uso e apropriando-se do conhecimento científico.

\section{Currículo da Escola do Campo}

A educação que se realiza nas Escolas do Campo é construída e estruturada com base nos conhecimentos comuns a todos os alunos, mas com o enfoque voltado aos saberes populares do grupo ao qual se destina. Então, "educação 
popular valoriza o conhecimento enquanto instrumento de ação sobre a realidade em transformação e enquanto resultado deste mesmo processo" (STRECK, 2005, p. 74) Neste sentido, a educação do campo, com base na educação popular, é compreendida a partir da intencionalidade que tem em relação à educação que quer, ao sujeito que quer e à sociedade que quer. Ou seja, parte do pressuposto de que é preciso conhecer, ter informação e saber usá-la, conseguindo intervir na sua realidade.

O currículo da escola do campo da rede estadual no município de Giruá/RS é elaborado a partir dos conhecimentos dos componentes curriculares da base comum, e é composto também pelo currículo oculto que é aquilo que está nas intencionalidades e posicionamentos que são tomados no processo de ensino-aprendizagem. Silva (2015, p. 78) afirma que "o currículo oculto é constituído por todos aqueles aspectos do ambiente escolar que, sem fazer parte do currículo oficial, explícito, contribuem, de forma implícita, para aprendizagens sociais relevantes". Faz parte deste currículo o efetivo trabalho pedagógico, desde o planejamento até a realização das atividades durante e após as aulas, e perpassa as intencionalidades, objetivos e a postura pedagógica do professor. Sobressaem-se o dinamismo das aulas e a relação que se estabelecem entre os sujeitos da aprendizagem e com a comunidade onde a escola do campo está inserida. Silva (2015, p. 150) expõe que:

O currículo é lugar, espaço, território. O currículo é relação de poder. O currículo é trajetória, viagem, percurso. O currículo é autobiografia, nossa vida, curriculum vitae: no currículo se forja nossa identidade. O currículo é texto, discurso, documento. O currículo é documento de identidade.

O currículo da escola do campo, neste sentido, é definido e construído, também, a partir da intencionalidade do fazer pedagógico, pois é uma forma de conscientização e de desenvolvimento individual e coletivo, que se firma na informação, na construção de saberes e no uso destes saberes para a transformação. O currículo compreende, então, todas as vivências realizadas na escola e fora dela, todas aquelas que são de forma intencional, planejadas e com objetivos definidos, e também aquelas vivências que acontecem de forma espontânea e sem um planejamento prévio. Os saberes populares iniciais, que 
são socializados e vão sendo em muitas vezes passados de geração em geração, ainda são parte constitutiva do currículo. Assim, o currículo é compreendido como uma trajetória de vida.

Pensar em transformação é pensar em mudanças, é alterar o que já está pronto, é modificar. Assim, como transformação em educação entende-se as mudanças que ocorrem nos sujeitos do processo de aprendizagem. Mudanças nas compreensões, no pensamento, no entendimento, na postura, ou seja, mudanças visíveis ou não, mas que, de alguma forma, modificaram de certo modo o sujeito. Com isso, é necessário buscar a transformação dos sujeitos na educação e pretender causar uma ruptura por menor que seja na intencionalidade de mexer com o que já está predefinido e que pode ser alterado. Arroyo (2004, p. 14 apud ARROYO; CALDART; MOLINA, 2004) escreve sobre a intencionalidade da escola:

A escola pode ser um lugar privilegiado de formação, de conhecimento e cultura, valores e identidades das crianças, adolescentes, jovens e adultos. Não para fechar-lhes horizontes, mas para abri-los ao mundo desde o campo, ou desde o chão que pisam. Desde suas vivências, sua identidade, valores e culturas, abrir-se ao que há de mais humano e avançado no mundo.

A escola do campo, em especial, é um lugar privilegiado, pois tem como foco a aprendizagem dos sujeitos do campo, com sua formação voltada aos conhecimentos e à cultura, aos valores e a identidades dos sujeitos do campo, sejam crianças ou adolescentes, ou até mesmo as suas famílias, que, como parceiras são coadjuvantes no processo de ensino-aprendizagem. Isso quer dizer que a escola tem muitas possibilidades de trabalho, trazendo as famílias e os parceiros dos agricultores, e indo até eles com visitações e aulas de campo nas propriedades dos alunos.

A Escola do Campo, aliada com seus parceiros, tem inúmeras possibilidades de construir os conhecimentos com base na realidade e nos saberes do grupo. Isso se caracteriza claramente quando são organizadas visitações nas 
propriedades dos alunos para que os familiares possam, junto com os professores, explicar o funcionamento da propriedade, modos de produção e relacionar tudo o que se pode aos conhecimentos científicos que são ensinados na escola.

As aulas práticas in loco fazem com que os estudos realizados se tornem mais atrativos e prazerosos. As questões sociais e de meio ambiente precisam permear sempre as discussões pois, para o meio rural, elas são norteadoras dos trabalhos na agricultura. Assim, a escola do campo, segundo Arroyo (2004, p. 54 apud ARROYO; CALDART; MOLINA, 2004), tem como “...papel da escola... compromisso ético/moral... compromisso com a intervenção social... compromisso com a cultura do povo do campo...". Ou seja, cabe à escola com o seu grupo de professores refletir sobre o compromisso que têm com as famílias e a comunidade na qual está inserida, para que, juntos, possam construir permanentemente o currículo da escola a partir das experiências que se obtêm, das necessidades e intencionalidades.

As possibilidades de trabalho nas escolas do campo são inúmeras, pois, na perspectiva de foco na educação popular, favorece e define como ponto de partida os saberes populares do grupo onde a escola está inserida, assim, ela parte dos saberes locais, individuais e coletivos para os conhecimentos globais, abrindo os horizontes. Nesse sentido, Streck (2005, p. 73) afirma que: "A educação popular parte do pressuposto de que o povo é possuidor de cultura e saber". Os conhecimentos que o grupo possui são muito importantes, pois, muitas vezes, têm relação com o conhecimento cientifico e não se percebe. Valorizar o conhecimento trazido pelos alunos é fundamental para o processo de ensino-aprendizagem.

O currículo da escola do campo funde em si os conhecimentos científicos e os saberes populares, além da intencionalidade na formação dos sujeitos nas questões sociais, culturais, políticas, cuidado e preservação do meio ambiente, relações pessoais e interpessoais, além da relação que estabelecem com o meio ambiente. Nesse ensino-aprendizagem se ensina e se aprende mais nas relações e trocas que se estabelecem no processo do que diretamente nos conteúdos definidos pelos currículos. Pois esse processo não tem muros e nem limites, é 
uma relação de aprendizagem que ultrapassa a escola e sua vizinhança e vai ao mundo, do local ao global. Arroyo (2004, p. 53 apud ARROYO; CALDART; MOLINA, 2004) assevera que:

Estamos entendendo por escola do campo aquela que trabalha os interesses, a política, a cultura e a economia dos diversos grupos de trabalhadores e trabalhadoras do campo, nas suas diversas formas de trabalho e de organização, na sua dimensão de permanente processo, produzindo valores, conhecimentos e tecnologias nas perspectivas do desenvolvimento social e econômico igualitário desta população. A identificação política e a inserção geográfica na própria realidade cultural do campo são condições fundamentais de sua implementação.

Arroyo (2004 apud ARROYO; CALDART; MOLINA, 2004) afirma então, que a escola do campo trabalha a partir dos interesses do grupo onde está inserida, da política, da cultura e da economia, além das diferentes formas de trabalho e produção existentes no grupo e outras possibilidades de trabalho e de organização; isso tudo para produzir valores, conhecimentos, tecnologias e perspectivas de futuro com desenvolvimento social e econômico para as pessoas. Lopes e Macedo (2011, p. 148) afirmam que:

a escola é vista como um espaço em que sentidos e ações são construídos por intermédio da interação entre os sujeitos, (...) mas amplia suas análises em direção às culturas (ou subculturas, na linguagem do autor) que penetram na escola como culturas de pertencimento dos sujeitos.

Esse pertencimento se refere aos seus grupos iniciais, ou seja, as suas famílias, amigos, comunidades culturais e sociais, as quais fazem parte. Nesse sentido, a responsabilidade social da escola do campo é muito grande, porque sai da esfera educativa apenas e torna-se abrangente como um agente de conscientização e de mobilização social, e em nenhum momento pode ser neutra ou tomar uma posição de neutralidade, pois é formadora de sujeitos, ou seja, das novas gerações do campo, que irão viver, produzir, cuidar de um espaço físico tão importante para a manutenção da vida no planeta. 
A partir da pesquisa realizada, o currículo da escola do campo analisada demonstra que é efetivamente na ação pedagógica, no planejamento, na intencionalidade e no currículo oculto que as relações com o meio e com os saberes populares se estabelecem. Lopes e Macedo (2011, p. 152) destacam que:

qualquer currículo formal é reescrito pelo professor, na medida em que ele reflete sobre a sua prática docente. Assim, o docente se configura como formulador do currículo vivido nas escolas e a separação entre desenvolvimento e implementação curricular torna-se sem sentido.

É nesse enfoque que se identificou que a ação do professor, a forma de condução, planejamento e intencionalidades do ato pedagógico, é que efetivamente produzem o currículo vivido na escola, em especial na escola do campo. Planejando as ações voltadas ao lugar, aos saberes populares, às vivências do campo, configuram e fazem relação entre o currículo formal e o currículo vivido na escola. Com isso, é a ação do professor e o seu posicionamento crítico que formula e reformula constantemente o currículo realizado nas escolas.

\section{Referências}

ARROYO, Miguel Gonzalez; CALDART, Roseli Salete; MOLINA, Mônica Castagna (Org.). Por uma Educação do campo. Petrópolis, RJ: Vozes, 2004. 214 p.

BRASIL. Diretrizes Curriculares Nacionais da Educação Básica. Brasília: MEC, SEB, Dicei, 2013. 562 p.

$81 \mathrm{p}$.

.Educação do Campo: diferenças mudando paradigmas. Brasília: MEC, 2007.

LOPES, Alice Casimiro; MACEDO, Elizabeth. Teorias de Currículo. São Paulo: Cortez, 2011. 279 p.

SANTOS, Milton. A Natureza do Espaço: Técnica e Tempo, Razão e Emoção. 4. Ed. São Paulo: Ed USP, 2012. 384p.

SILVA, Tomaz Tadeu. Documentos de identidade: Uma introdução às teorias do currículo. 3. Ed. Belo Horizonte: Autêntica Editora, 2015. 156 p.

STRECK, Danilo R. Correntes pedagógicas: Uma abordagem interdisciplinar. 2 ed. Petrópolis: Vozes, 2005.

Recebido em: 12/12/2016

Aceito em:15/7/2017 